\title{
Fundo previdenciário e impacto orçamentário no serviço público
}

\section{Introdução}

Os sistemas de aposentadorias e pensões dos servidores públicos têm ocupado um espaço especial nas agendas da reforma da previdência e da reforma administrativa. Como se sabe, uma parte substancial dos funcionários da União, dos estados e dos municípios encontra-se fora do regime previdenciário geral, sendo suas aposentadorias pagas diretamente pelo Tesouro. $\mathrm{O}$ peso crescente dos encargos com aposentadorias e pensões nas folhas de pagamento, nos diversos níveis da administração pública, tem estimulado a discussão de regimes previdenciários alternativos. Mesmo antes da aprovação da Lei 9.717, que estabeleceu novos parâmetros para o sistema previdenciário do serviço público, alguns estados vinham promovendo estudos e procurando implantar planos de custeio e de benefício de menor custo orçamentário.

O Estado de São Paulo acompanhou a tendência à revisão dos esquemas de proteção social dos servidores e iniciou estudos visando a implantação de um fundo de previdência, a ser balizado pelo quadro legal do Projeto de Emenda Constitucional - PEC 33. Os objetivos imediato e mediato do novo fundo, modelado ao longo de 1998, seriam o de sustar o crescimento da participação dos pagamentos a inativos no total de despesas do estado, e de desonerar progressivamente o orçamento do encargo com aposentadorias. Tudo indica que as discussões sobre o fundo se estenderão ao longo de 1999, incorporando as novas disposições estabelecidas pela Lei 9.717.

Antes mesmo dessa iniciativa, as universidades estaduais paulistas demonstravam interesse na discussão de uma alternativa própria de

Professor adjunto do Instituto de Economia da Universidade Estadual de Campinas/ Unicamp 
financiamento previdenciário. As universidades tinham razões próprias para essa preocupação com o regime previdenciário. Em primeiro lugar, o regime ainda em vigor implica um recolhimento equivalente a $14 \%$ da folha de pagamento dos servidores ao IPESP (Instituto de Previdência do Estado de São Paulo) e ao IAMSPE (Instituto de Assitência Médica ao Servidor Público do Estado), entidades que oferecem um retorno em serviços reduzido, desproporcional aos elevados valores arrecadados. A situação vivida pelas universidades é anacrônica, pois elas arcam com $8 \%(6+2)$ de encargos patronais e ainda pagam a totalidade das aposentadorias dos servidores estatutários, para não mencionarmos os onerosos serviços médicos custeados por recursos orçamentários.

Em segundo lugar, o interesse por um fundo próprio deveu-se à maior compatibilidade com o princípio de autonomia orçamentário-financeira, em especial com a manutenção de políticas de pessoal e remuneração próprias. Vale lembrar que desde 1989 as universidades paulistas vivem uma experiência pioneira de autonomia orçamentária e financeira, que envolve transferências automáticas de recursos do Tesouro, vinculadas à arrecadação do ICMS, e autoridade para a formulação de uma política salarial específica.

A experiência da autonomia, em particular o mecanismo de vinculação de receitas, gerou um horizonte de previsibilidade orçamentária inédito no interior da administração pública. Gerou também — o que é o ponto de partida para a elaboração deste estudo — a possibilidade de fixação do tamanho do serviço público, um elemento essencial para a discussão dos novos regimes previdenciários.

Ao transitar-se para uma nova sistemática de aposentadorias e pensões, a definição dos custos de transição de regime depende não apenas do novo quadro de direitos e da situação atuarial dos servidores, mas também do tamanho do serviço público a ser mantido. Não é difícil ajustar o custo da transição à escassez de recursos do serviço público comprimindo o quadro de servidores e o volume de serviços oferecidos. Contudo, essa metodologia não fornece uma exata medida do custo de transição, e sim uma medida mista, que confunde os impactos do novo regime com as economias proporcionadas pela redução do contingente funcional (ou pela redução dos salários reais dos servidores, o que é o mesmo). Devido à regra peculiar de vinculação de receitas tributárias, na universidade tornou-se viável medir o custo de transição efetivo, definido como o montante de recursos necessários à implantação de um regime previdenciário que contemple a sustentação orçamentária da administração pública, fixado o valor (preços x quantidade) dos serviços a serem oferecidos.

O objetivo do presente artigo é a formulação de um modelo de fundo previdenciário para o serviço público, aplicado à Universidade 
Estadual de Campinas (Unicamp). Além da já mencionada possibilidade de fixarmos o tamanho da Universidade, a vantagem de circunscrevermos a análise a uma única entidade do serviço público é a relativa disponibilidade de informações. O orçamento da Unicamp proporciona as informações gerais necessárias à elaboração de uma medida dos custos orçamentários da transição, o que é decisivo na falta de dados demográficos e atuariais mais acurados.

Apesar de o modelo estar circunscrito a uma entidade específica do serviço público, acredito que não seria difícil estendê-lo a outros segmentos, com as devidas adaptações, desde que se possa definir o tamanho do serviço público, caso a caso. Tanto o corpo do artigo quanto os anexos explicitam do modo mais aberto possível os dados utilizados e a construção de variáveis. Existe, ainda, uma preocupação especial em discutir a solidez dos parâmetros. Quer dizer, se os pressupostos do modelo forem considerados válidos, não haverá dificuldade em adaptá-lo a outros segmentos.

Do mesmo modo, o sistema de direitos que balizou as projeções está devidamente identificado. No fundamental, o modelo assumiu a vigência da legislação atual, o que significa garantia de aposentadorias ao nível da posição funcional do final da carreira, tratamento análogo para ativos e inativos, e validade do regime de tempo de serviço. ${ }^{1}$ Não há nenhuma dificuldade em considerar um quadro de direitos distinto - o próprio artigo incorpora algumas variações — bastando alterar os parâmetros utilizados.

Mais do que efetuar uma medida do custo da transição para um segmento específico do serviço público, o propósito do trabalho é a discussão de alguns dos fundamentos dos regimes previdenciários, a partir de bases mais concretas. Na verdade, a atual reforma da previdência vem sendo feita aos trancos e barrancos, sem uma revisão conceitual satisfatória das alternativas em votação e de suas implicações. No que se refere aos servidores públicos, tem havido um descompasso entre a discussão das regras que regem a carreira funcional e das regras que definem o regime previdenciário, embora muitas das inconsistências do atual sistema não derivem das regras de previdência, e sim da estrutura das carreiras. Enfim, a crise da previdência pública é uma crise combinada do regime orçamentário e do financiamento previdenciário. Ao se concentrar no impacto orçamentário de um regime de fundo, e não nos critérios atuariais de sustentação de um fundo, $\mathrm{o}$ artigo pretende contribuir para situar o debate sobre a previdência dos servidores no ambiente mais amplo (e mais proveitoso) das condições de financiamento do serviço público.

\section{A relação fundo-orçamento}

Uma apresentação pormenorizada das relações entre o fundo e o orçamento é um bom ponto de partida, já que a principal fonte de motivação 
para a instituição de fundos de benefícios é a expectativa de redução da sobrecarga que o pagamento das aposentadorias impõe ao orçamento. No regime atual, o sistema previdenciário onera a Unicamp de dois modos: por um lado, a responsabilidade integral pelo pagamento de aposentadorias dos servidores estatutários recai sobre o orçamento; por outro, o recolhimento das contribuições patronais ao IPESP e ao IAMSPE constitui uma despesa orçamentária corrente, sem retorno. Com a instituição de um fundo previdenciário próprio, o recolhimento mensal ao IPESP e, eventualmente, ao IAMSPE seria substituído por um repasse ao fundo, conforme alíquota a ser estipulada; além disso, mantido o princípio de definição dos benefícios, ${ }^{2}$ o patrocinador teria que cobrir os eventuais saldos negativos, ou seja, efetuar as transferências necessárias à solvência do fundo.

Do ponto de vista das condições de financiamento, essa sistemática é semelhante à que vinha vigorando nos fundos de pensão das empresas estatais, em que empregadores e trabalhadores contribuem e o empregador arca com as eventuais transferências necessárias ao equilíbrio do fundo. Existe solidariedade orçamentária, ou seja, uma vez definidos os benefícios e as contribuições, o empregador garante a solvência do sistema. $\mathrm{O}$ esquema pode requerer uma significativa participação patronal no fundo, seja na forma de contribuições mensais, seja na forma de repasses extraordinários para ajustar os fluxos de pagamento aos valores capitalizados; aliás, os fundos das empresas estatais vinham sendo questionados exatamente pelo elevado ônus orçamentário envolvido. Como se verá adiante, as simulações apresentadas no artigo tomam como ponto de partida a manutenção de uma distribuição eqüitativa do ônus entre empregado e empregador, o que estabelece uma espécie de barreira, limitando o impacto orçamentário.

De todo modo, o que define o núcleo do modelo não é a maneira pela qual o ônus previdenciário entre empregados e empregadores é repartido, e sim a solidariedade entre o orçamento e o fundo, imposta pelo regime de benefícios definidos. Havendo definição de benefícios, é sempre o patrocinador (o orçamento) quem garante o equilíbrio entre os fluxos de entrada e saída de recursos. Se houver uma certa regularidade no comportamento das principais variáveis econômicas envolvidas no orçamento e no fundo - nível da receita, valor real dos salários e dos benefícios, etc. - é possível zerar as transferências adicionais do patrocinador, vale dizer, manter o equilíbrio atuarial com base somente nas alíquotas de contribuição. O regime de benefícios definidos aproxima o modelo de fundo da situação hoje em vigor, no sentido de que prevalece a garantia orçamentária; contudo, uma das virtudes do fundo é explicitar as responsabilidades de empregado e empregador, algo que é difícil em um regime orçamentário puro. No modelo proposto, qualquer insuficiência do fundo 
deve ser enfrentada por uma elevação da contribuição do empregado ou por transferências orçamentárias adicionais, sendo que estas últimas requerem uma redução dos vencimentos dos servidores ativos e inativos. Em todas as situações, o ônus é sempre identificado e acaba recaindo sobre os servidores.

A estabilidade e a auto-regulamentação do regime de fundo não eliminam o custo da transição, representado pelo passivo previdenciário dos servidores ativos no velho regime. No modelo apresentado, os recursos para fundar a inclusão dos servidores do quadro de transição no fundo estão postos a débito do orçamento e compõem o passivo orçamentário global, o que não significa que a universidade tenha condições de arcar com um compromisso adicional tão significativo a partir de seus recursos orçamentários convencionais. O propósito da colocação dos custos de transição a débito do orçamento foi somente o de explicitar a responsabilidade do empregador, em um regime que opera com garantia de benefícios.

Duas observações adicionais sobre a solidariedade entre orçamento e fundo. Em primeiro lugar, a solidariedade não se esgota nos repasses orçamentários necessários, dada a garantia de benefícios. Como foi dito, qualquer medida do custo da transição requer a definição do tamanho do serviço público. Já que a universidade é uma prestadora de serviços públicos a partir das transferências tributárias, a transição só pode ser modelada se associarmos o tamanho modular da universidade a um determinado volume de recursos tributários e de despesas orçamentárias. Nas simulações efetuadas, o ano-base escolhido foi 1998, o que significa que o volume de serviços prestados, o valor real de salários e benefícios e, principalmente, o nível de emprego, estão vinculados aos parâmetros orçamentários de 1998.

Algumas regras estabelecem a relação entre o volume de serviços e seu custo unitário. Vale notar que, como a medida dos serviços pode ser fixada por indicadores acadêmicos convencionais (número de matrículas, atividades de pesquisas, serviços de extensão oferecidos etc.), o nível de emprego na universidade representa a variável crítica por excelência. Em relação a ela, a fixação dos parâmetros do ano-base tem uma conseqüência bem definida: os acréscimos da folha de inativos não serão compensados por uma redução do número de servidores ativos.

A rigor, a relação entre o volume de serviços e seu custo unitário está especificada em uma série de condições, que podem ser entendidas como as restrições do modelo (dados os parâmetros do ano-base):

- serviços adicionais (e contingentes de servidores ativos adicionais) dependerão estritamente de uma expansão do valor real das transferências tributárias ou de acréscimos na produtividade do sistema, sempre explicitados;

— os salários e aposentadorias em vigor no ano-base representam o teto dos vencimentos; ${ }^{3}$ 
— os vencimentos dos servidores ativos e inativos serão flexíveis à baixa, o que significa que as eventuais reduções do valor real das transferências tributárias serão enfrentadas com redução dos vencimentos, e não do número de servidores.

A política de reposição dos servidores aposentados é o ponto sensível por detrás desses itens. É sabido que a universidade pode enfrentar a pressão orçamentária das aposentadorias simplesmente deixando de repor servidores, até o ponto em que sobrevenha uma redução dos serviços prestados ou uma diminuição de sua qualidade (fechamento de turmas, redução de matrículas, diminuição dos atendimentos à comunidade). O modelo exclui essa possibilidade, quer dizer, compromete-se com a reposição de servidores em nível compatível com os serviços prestados no ano-base.

Uma segunda observação remete ao sentido da expressão "benefícios definidos", que vem sendo utilizada com excessiva liberdade no debate previdenciário geral, e mesmo no presente artigo. A regra constitucional em vigor, bem como a hipótese adotada no modelo, apenas vincula as aposentadorias aos salários dos servidores ativos. Isso implica uma equivalência entre os índices de reajuste dos vencimentos do pessoal ativo e inativo, porém, de modo nenhum significa que os benefícios não flutuarão para baixo. Como os vencimentos reais dos servidores continuam a oscilar na vigência do novo regime, nada assegura que o (último) salário de contribuição venha a ser a medida dos benefícios no período de inatividade. Em resumo, não há garantia de manutenção dos benefícios reais dos servidores inativos simplesmente porque não há garantias para os salários dos trabalhadores em atividade — uma característica do regime atual, a ser mantida no futuro. Mais ainda, como o modelo admite apenas a possibilidade de flutuação dos salários à baixa, não é impossível que as aposentadorias sejam desproporcionais aos salários de contribuição e às contribuições efetuadas, em detrimento dos aposentados.

No contexto do modelo, assim como nas regras previdenciárias atuais, definição de benefícios representa apenas a existência de uma regra vinculando o valor dos recebimentos mensais aos salários dos servidores ativos, e nunca a garantia de rendimentos reais. A usual contraposição entre "benefícios definidos" e "contribuição definida" não descreve de modo adequado a situação, exatamente porque o regime previdenciário em vigor na administração pública, bem como o modelo aqui proposto, admitem flutuações dos valores das aposentadorias independentemente das contribuições prévias efetuadas. Assim, se as regras acima apresentadas como restrições ao modelo forem obedecidas, não haverá pressão orçamentária ou inconsistência atuarial no sistema, apesar da vinculação entre os salários de servidores ativos e inativos. Do 
ponto de vista da garantia de solvência do fundo sem pressão sobre o patrocinador - e apenas desse ponto de vista - o modelo proposto emula o princípio da contribuição definida.

A rigor, o modelo exige que o valor real dos salários de referência dos servidores ativos e inativos flutue para baixo ao sabor do valor real das transferências tributárias - mas apenas por essa razão. ${ }^{4}$ De modo mais preciso, os salários e benefícios estão indexados, para baixo, ao ICMS, enquanto as variações positivas do ICMS (em relação aos valores do ano-base) são destinadas à expansão da universidade. Na alta, a transferência de recursos tributários é o indexador do tamanho da universidade; na baixa, é o indexador dos salários.

\section{O que é peculiar à Unicamp}

A particularidade mais marcante na política previdenciária em vigor nas universidades paulistas é que o empregador é o responsável pelo pagamento de salários e aposentadorias, enquanto o IPESP e o IAMSPE, instituições que recebem as contribuições, respondem somente pela pagamento de pensões e pelo atendimento médico. Outras particularidades da estrutura de salários e benefícios da Unicamp são as seguintes:

- A Unicamp é uma instituição jovem. As expansões mais significativas do quadro de pessoal ocorreram entre 1984/90 e, em decorrência, o ônus dos encargos com aposentadorias (17\% da folha de pagamentos global, em 1998) ainda não atingiu o máximo.

- A participação dos funcionários não-docentes é expressiva, tanto no contingente global de servidores (77\%) quanto na folha de pagamentos $(55 \%)$. Essa distribuição é paradoxal, em se tratando de uma instituição de ensino, mas produz dois resultados positivos: a) o período de vida ativa e de contribuição dos não-docentes excede o dos docentes; b) enquanto a quase totalidade do quadro docente é composta por servidores estatutários, uma considerável fração dos servidores não-docentes está filiada ao regime previdenciário geral.

- Apesar de disporem de autonomia financeira, as universidades não regulamentam a totalidade do regime funcional e de direitos dos servidores. Aplicam-se a elas as regras gerais do serviço público paulista, que incluem dois pontos de grande impacto: a) concessão de acréscimos salariais de $5 \%$ (não-cumulativos) a cada quinqüênio de atividades no serviço público estadual, afora um maxi-acréscimo de $16 \%$ aos vinte anos de serviço; b) incorporação de gratificações de chefia aos salários e, por extensão, às aposentadorias, após 5 anos (contínuos ou não) de exercício do cargo gratificado, sempre no valor da maior gratificação obtida. ${ }^{5}$ 
- Os adicionais por tempo de serviço e as gratificações incorporadas somam-se à progressão funcional ordinária e representam um acréscimo significativo aos vencimentos, no período final da carreira do servidor. Além do crescimento vegetativo não desprezível da folha, essa escala de progressão provoca um grande fosso entre o salário médio de contribuição do servidor e o valor médio de seus benefícios.

- Como foi dito, a fonte principal de recursos da Unicamp são as transferências de ICMS do governo paulista. Recursos suplementares existem, mas não se comunicam com as folhas de pagamento dos servidores e têm, quase todos, natureza extra-orçamentária. Os exemplos mais representativos são os convênios por prestação de serviços de pesquisa e/ou extensão universitária, sempre efetuados em regime de custeio parcial, vale dizer, cobrindo as despesas efetivamente realizadas exclusive a remuneração básica do pessoal universitário. Em suma, os recursos adicionais às transferências do governo do Estado não podem ser postos à disposição do orçamento e, em conseqüência, não afetam as simulações.

\section{O modelo}

Uma projeção mais acurada do impacto das aposentadorias exigiria a realização de estudos demográficos abrangendo o universo dos servidores ativos e inativos, além da utilização de variáveis de natureza atuarial, inclusive cenários de capitalização. O modelo procura tirar o máximo proveito das escassas informações disponíveis, que são, basicamente, aquelas referentes à folha de pagamentos: números de servidores docentes e nãodocentes ativos e inativos e respectivas folhas salariais; proporção da folha de pagamentos destinada aos servidores celetistas; salários médios. A maior parte dessas informações consta do Orçamento de 1998 da Unicamp, construído com base em projeções bastante acuradas.

Algumas variáveis-chave, como o ritmo de passagem da atividade à inatividade no quadro de transição e a escala de exclusões dos aposentados do orçamento, foram inferidas com certa segurança, porque é possível terse uma idéia da distribuição das contratações no tempo. Para o cálculo da progressão na carreira - o que envolve promoções, adicionais por tempo de serviço, gratificações - foi considerada a relação entre valores médios dos vencimentos dos inativos e ativos, nas categorias docentes e não-docentes. Esse não é um indicador acurado do crescimento vegetativo da folha (ver Anexo 1), mas é a informação mais confiável. ${ }^{6}$

$\mathrm{O}$ modelo, basicamente, estabelece vínculos interativos entre o orçamento e o fundo ao longo de 30 anos. O ponto de referência é a situação em $\mathbf{t}_{\mathbf{0}}$ (1998), na qual o fundo não existe, todos os aposentados 
estão a encargo do orçamento e as contribuições oneram os empregados e a folha de pagamentos, sem capitalização a favor do orçamento. $\mathrm{O}$ núcleo operacional do modelo é o seguinte: a partir do período inicial $\left(\mathrm{t}_{1}\right)$, efetua-se a transferência de sucessivas frações da folha de pagamentos, do orçamento para o fundo de aposentadorias, considerados os devidos ajustes de encargos e os vetores de mudança de estado. Estes vetores modulam o ritmo de passagem da atividade à inatividade e de incorporação de novos servidores em substituição aos aposentados. Observe-se que toda a movimentação de servidores de uma situação à outra — aposentadorias, cessação de benefícios, contratações - é representada em valores, e não em número de servidores, porque o modelo só opera com frações da folha de pagamentos.

Vale lembrar que a constituição de um fundo previdenciário envolve três grupos em situação distinta quanto a direitos e benefícios no momento da transição: o dos servidores já aposentados, o dos servidores ativos no ano-base (quadro de transição) e o dos servidores a serem contratados na vigência do novo regime. O primeiro grupo tem direito à aposentadoria integral até a morte, não existindo outra alternativa a não ser mantê-lo a encargo do orçamento, com as devidas exclusões por morte dos beneficiários. O grupo dos servidores em atividade é o que projeta um déficit atuarial sobre o novo fundo, na medida em que as futuras contribuições capitalizadas não serão suficientes para a garantia dos benefícios, devido ao pequeno período de contribuição. Finalmente, para o grupo dos servidores contratados conforme as novas regras vale, por hipótese, a suposição de compatibilidade atuarial entre contribuições e benefícios.

O quadro de transição é o que de fato interessa ao modelo. Os servidores desse quadro contribuíram ao longo da vida funcional para um fundo de benefícios (IPESP) que não proporciona qualquer retorno à universidade ou ao fundo a ser criado. Sua inclusão no fundo deveria vir acompanhada de um crédito, no mínimo correspondente ao valor capitalizado das contribuições (patronal e individual) efetuadas. Ocorre que a definição dos direitos não é um assunto trivial, quando menos porque as contribuições do passado reportam-se a pensões, e não a aposentadorias. Na constituição do fundo, uma das possibilidades é o governo do estado decidir responsabilizar-se pelo pagamento das pensões, que representam uma fração quase desprezível do bolo de benefícios, atribuindo ao fundo o encargo das aposentadorias. Em suma, a universidade nada pode reivindicar, porque continuaria a arcar apenas com um encargo que já era seu. É claro que essa é uma interpretação bastante desfavorável à universidade e que pode ou não vir a se impor, mas o importante é destacar que as garantias de obtenção dos recursos necessários à transição de regime são pouco sólidas. 
O grupo dos servidores a serem contratados na vigência do novo regime é o que menos afeta o modelo. Pelo fato de estarmos supondo que as contribuições serão capitalizadas em um subfundo à parte, integralmente destinado ao pagamento de benefícios do grupo, as contribuições em nome dos novos servidores podem ser ignoradas na apuração dos resultados do fundo. Isso não significa que o impacto orçamentário do novo grupo possa ser inteiramente desconsiderado, pois deve haver um acréscimo dos encargos sociais em relação à situação atual. Por outro lado, as contratações em reposição sempre representam um encargo adicional, se considerarmos que o vencimento do servidor que se aposenta desonera o orçamento mas passa a constar a débito do fundo.

Outra hipótese do modelo é a de que as alíquotas de contribuição referentes aos novos contratados são extensivas aos servidores do quadro de transição, por uma questão de isonomia salarial. Portanto, dado o nível salarial, as alíquotas definem, pelo lado da contribuição patronal, o custo orçamentário do quadro de transição e do quadro de novos servidores, definindo também a receita do fundo, para não falarmos da renda líquida dos servidores novos e antigos. Cabe advertir que a contribuição atuarial de sustentação para o contingente dos novos contratados adotada nas simulações não está embasada em estudos específicos. A alíquota inicialmente utilizada, de 24\% $(12+12)$, é meramente intuitiva: é razoável imaginar que qualquer alíquota abaixo desse piso seja incapaz de sustentar benefícios integrais e, por outro lado, $12 \%$ parece representar um máximo admissível para as contribuições individuais, pois de outro modo haveria uma considerável redução do salário líquido. Como salvaguarda, as simulações consideram o impacto de alíquotas alternativas.

O período de 30 anos utilizado nas projeções é suficiente para a absorção do grupo de transição no fundo e para a renovação do quadro, nos novos moldes. Em termos práticos, trinta anos é o período necessário para passar os servidores hoje ativos para a aposentadoria. Supusemos que neste mesmo intervalo uma pequena parcela dos servidores do quadro de transição será eliminada do fundo (por morte), e que os servidores hoje inativos serão passo a passo exonerados do orçamento (também por morte).

Todas as informações básicas e o cálculo dos resultados foram distribuídas em três planilhas interativas:

— na planilha Variáveis estão os dados utilizados nas simulações, abrangendo as informações certas e as hipóteses de trabalho. As informações certas são aquelas retiradas do orçamento de 1998: valor da folha de pagamentos para docentes e não-docentes, ativos e inativos; encargos salariais; taxa atual de participação das aposentadorias na folha de pagamentos; proporção da folha de pagamentos referente a servidores celetistas (cuja aposentadoria não onerará o fundo). ${ }^{7}$ As hipóteses de trabalho são: as taxas médias de progressão salarial para docentes e 
não-docentes; as alíquotas de contribuição para o fundo; os vetores de transição de estado. Há quatro vetores de transição de estado: o vetor de exclusão dos servidores já aposentados do orçamento; o vetor de transição dos servidores ativos ao fundo; o vetor de exclusão dos servidores em transição do fundo; o vetor de contratações em reposição.

- a planilha Orçamento projeta todos os fatores de expansão (a débito) e de contração (a crédito) da folha de pagamentos, de $t_{1}$ a $t_{30}$, em relação ao ano-base. Fatores de contração: exclusões dos aposentados da folha de pagamentos (por morte); passagem dos servidores do quadro de transição ao fundo (por aposentadoria). Fatores de expansão: diferença entre os encargos sociais em $t_{0}$ e nos períodos subseqüentes; novas contratações (inclusive encargos); progressão salarial dos servidores ativos em $\mathrm{t}_{0} \mathrm{e}$ ainda em atividade nos períodos considerados; progressão salarial dos servidores a serem contratados a partir de $t_{1}$. A compensação entre os fatores de expansão e os de contração origina um saldo orçamentário, que retrata, ano a ano, exatamente as "economias" (quando positivo) e as "deseconomias" (quando negativo) em relação à situação atual. Na medida em que os encargos foram aumentados de uma vez só e os servidores inativos em $\mathrm{t}_{0}$ desonerados do orçamento passo a passo, além de o quadro estar sendo renovado com controle, é de esperar que o saldo orçamentário exiba economias nos primeiros anos e deseconomias nos demais.

- a planilha Fundo contabiliza todas as receitas e despesas do fundo, excluindo as contribuições nominais aos novos servidores, que serão capitalizadas no subfundo à parte, já mencionado. A crédito: contribuições sociais (patronais e individuais) dos servidores do quadro de transição; exclusões do fundo por morte dos servidores que vieram do quadro de transição. A débito: valor das aposentadorias dos servidores do quadro de transição. Notar que não há exclusão de servidores contratados na vigência do novo regime, porque o período de 30 anos não é suficiente para tanto. A planilha simula duas situações básicas: a primeira (A) assume aposentadorias equivalentes ao salário bruto da ativa - o que equivale a um acréscimo da renda líquida na aposentadoria, devido à nãoincidência de descontos previdenciários; e a segunda (B) assume equivalência entre os rendimentos líquidos dos ativos e inativos.

Abaixo são apresentados os componentes (descrição e valores) da planilha Variáveis, ${ }^{8}$ com os respectivos valores, e identificadas as colunas das planilhas Orçamento e Fundo, cujas fórmulas de cálculo e resultados numéricos constam dos Anexos 2 e 3 . É importante lembrar que a seriação abaixo em numerais romanos, que indica as colunas em cada planilha, será mantida e transportada às demais planilhas, quando for o caso. 


\subsubsection{Informações certas}

I. $\mathrm{FPB}_{\mathrm{DA}}$ - folha de pagamentos bruta dos docentes ativos: $\mathrm{R} \$ 112.435$ mil.

II. $\mathrm{FPB}_{\mathrm{DI}}$ - folha de pagamentos bruta dos docentes inativos: $\mathrm{R} \$ 31.218$ mil.

III. $\mathrm{FPB}_{\mathrm{NDA}}$ - folha de pagamentos bruta dos servidores nãodocentes ativos: $\mathrm{R} \$ 159.215$ mil.

IV. $\mathrm{FPB}_{\mathrm{NDI}}$ - folha de pagamentos bruta dos servidores não-docentes inativos: $\mathrm{R} \$ 17.351 \mathrm{mil}$.

$\mathrm{V}$. $\mathrm{FPB}_{\mathrm{DA}} \mathrm{NE}$ - proporção da folha de pagamentos bruta dos docentes ativos destinada a não-estatutários: 0,04.

VI. PFPB ${ }_{\mathrm{NDA}} \mathrm{NE}$ - proporção da folha de pagamentos bruta dos servidores não-docentes ativos destinada a não-estatutários: 0,56.

VII. $\mathrm{SM}_{\mathrm{DI}} / \mathrm{SM}_{\mathrm{DA}}$ - salário médio dos docentes inativos/salário médio dos docentes ativos: 1,46.

VIII. $\mathrm{SM}_{\mathrm{NDI}} / \mathrm{SM}_{\mathrm{NDA}}$ - salário médio dos não-docentes inativos/ salário médio dos não-docentes ativos: 1,19.

IX. TMPS D $_{\mathrm{D}}$ taxa média anual de progressão salarial para os docentes, ou crescimento vegetativo da folha. O cálculo da taxa média foi feito a partir da variável VII $\left(S M_{D I} / S M_{D A}\right)$, sob as hipóteses de que o quadro atual está formado por professores no meio da carreira e de que a distribuição dos acréscimos salariais é uniforme ao longo da carreira. Ambas as hipóteses não são reais, mas não há meios de obter o crescimento vegetativo anual efetivo em cada período de $t_{1}$ a $t_{30}$, mesmo porque essa informação depende da vida profissional anterior ao ingresso na universidade, o que condiciona os quinquênios e o intervalo de permanência na universidade: ${ }^{9} 0,025$.

X. TMPS $_{\mathrm{ND}}$ - taxa média anual de progressão salarial para os não-docentes, ou crescimento vegetativo da folha. O cálculo da taxa média foi feito a partir da variável VIII, aplicando-se as mesmas observações anteriores: ${ }^{10} 0,011$.

XI. TMPS ${ }_{\mathrm{DND}}$ - taxa média anual de progressão salarial para docentes e não-docentes (média geométrica das taxas anteriores, ver Anexo I): 0,0179.

XII. $\mathrm{FPL}_{\mathrm{DA}}$ - folha de pagamentos dos docentes ativos líquida dos encargos sociais: $\mathrm{FPB}_{\mathrm{DA}} / 1,08=\mathrm{R} \$ 104.106$ mil.

XIII. FPL $\mathrm{NDA}_{\mathrm{N}}$ - folha de pagamento dos não-docentes ativos líquida dos encargos sociais: $\mathrm{FPB}_{\mathrm{NDA}} / 1,08=146.069$ mil.

XIV. ACP - alíquota de contribuição patronal: 0,12.

XV.ACE - alíquota de contribuição individual: 0,12. 
XVI. TX DESC — taxa de descontos: 0,06.

\subsubsection{Hipóteses (vetores de transição de estado)}

XVIIA. Vetor de exclusão dos inativos da folha de pagamentos, de $t_{1} a t_{30}$ :

$\mathrm{t}_{1} \mathrm{a} \mathrm{t}_{10}-0,01 \quad \mathrm{t}_{16} \mathrm{a} \mathrm{t}_{20}-0.03 \quad \mathrm{t}_{26} \mathrm{a} \mathrm{t}_{30}-0.08$

$\mathrm{t}_{11}$ a $\mathrm{t}_{15}-0.02 \quad \mathrm{t}_{21}$ a t $_{25}-0.05$

XVIIB. Idem, acumulado.

XVIIIA. Vetor de aposentadorias no quadro de transição, de $t_{1}$ a $t_{30}$ :

$\mathrm{t}_{1} \mathrm{at}_{5}-0,03 \quad \mathrm{t}_{11}$ a $\mathrm{t}_{15}-0,05 \quad \mathrm{t}_{21}$ a $\mathrm{t}_{25}-0,03$

$\mathrm{t}_{6} \mathrm{at}_{10}-0,04 \quad \mathrm{t}_{16} \mathrm{at}_{20}-0,04 \quad \mathrm{t}_{26} \mathrm{at}_{30}-0,01$

XVIIIB. Idem, acumulado.

XIX. Vetor de exclusão (por morte) dos servidores do quadro de transição do fundo, de $t_{1}$ a $t_{30}$ :

$\mathrm{t}_{1}$ a t $_{20}-0,00$

$\mathrm{t}_{21} \mathrm{at}_{30}-0,01$

XXA. Incorporação de novos servidores:

$\mathrm{t}_{1} \mathrm{at}_{10}-0,01 \quad \mathrm{t}_{16}$ a $\mathrm{t}_{25}-0,03$

$\mathrm{t}_{11}$ a $\mathrm{t}_{15}-0,02 \quad \mathrm{t}_{26}$ a $\mathrm{t}_{30}-0,04$

NB: O novo servidor tem um custo orçamentário menor do que o que se aposenta, pois está no início da carreira. Além disso, a tabela comprime a taxa de reposição nos primeiros anos da série, o que supõe um aumento de produtividade (ver comentário adiante).

XXB. Idem, acumulado.

\subsection{Planilha Orçamento}

Nesta planilha estão incluídos todos os impactos a débito e a crédito no orçamento, tomando como base o orçamento em $\mathrm{t}_{0}$. As fórmulas de cálculo constam do Anexo 2 e os resultados numéricos do Anexo 3, Tabela A1. A identificação das colunas (mesma numeração nos Anexos) é o seguinte:

I. Folha salarial dos docentes do quadro de transição - considera os novos encargos e o crescimento vegetativo da folha e desconsidera o efeito das aposentadorias.

II. Folha salarial dos docentes do quadro de transição — considera os novos encargos e o crescimento vegetativo da folha e desconta o efeito das aposentadorias.

III. Variação da folha de pagamentos dos docentes do quadro de transição em relação ao ano-base .

IV. Folha salarial dos não-docentes do quadro de transição - considera os novos encargos e o crescimento vegetativo da folha $\mathrm{e}$ desconsidera o efeito das aposentadorias.

V. Folha salarial dos não-docentes do quadro de transição — considera os novos encargos e o crescimento vegetativo da folha e desconta o efeito das aposentadorias. 
VI. Variação da folha dos não-docentes do quadro de transição em relação ao ano-base.

VII. Morte dos servidores inativos no ano-base.

VIII. Novas contratações — impactos sobre a folha.

IX. Novas contratações — impactos acumulados sobre a folha, considerando-se a progressão salarial.

X. Saldo do orçamento.

\subsection{Planilha Fundo}

Nesta planilha está incluída toda a movimentação do fundo, em valores, referente aos servidores do quadro de transição. O saldo final leva em consideração duas hipóteses alternativas para o pagamento das aposentadorias: a equivalência entre os vencimentos brutos dos servidores ativos e inativos (Saldo $A$ ) e a equivalência entre os vencimentos líquidos (Saldo $B$ ). As fórmulas de cálculo constam do Anexo 2 e os resultados numéricos estão no Anexo 3, Tabela A2. A identificação das colunas (mesma numeração dos Anexos) é a seguinte:

I. Inclusão dos docentes do quadro de transição no fundo (salário bruto integral), excluindo os docentes celetistas.

II. Inclusão dos não-docentes do quadro de transição no fundo (salário bruto integral), excluindo os não-docentes celetistas.

III. Contribuição correspondente aos docentes do quadro de transição.

IV. Contribuição dos não-docentes do quadro de transição ao fundo.

V. Saldo A.

VI. Inclusão dos docentes do quadro de transição (salário líquido integral).

VII. Inclusão dos não-docentes do quadro de transição (salário líquido integral).

VIII.Saldo B.

\section{Resultados}

As Tabelas A1 e A2 (Orçamento e Fundo), no Anexo 3, contêm as tabulações para os valores originais das variáveis (conforme descrição anterior da planilha Variáveis). A Tabela 1, abaixo, transcreve os saldos do orçamento e do fundo e efetua a totalização dos saldos do orçamento e do fundo, a valores correntes e a valores presentes.

As duas últimas colunas da Tabela 1 - Saldo total $A$ e Saldo total $B$ a valores presentes - contêm os saldos consolidados de Orçamento e Fundo, de $t_{1}$ a $t_{30}$, descontados a uma taxa de de $6 \%$ ao ano. Na última linha está 
apresentado o somatório dos saldos totais nos conceitos A e B, a valores presentes de 1998, os quais refletem todos os impactos no orçamento e no fundo de $t_{1}$ a $t_{30}$, e podem ser considerados o verdadeiro custo orçamentário da transição de regime, na direção de um fundo auto-sustentado.

Tabela 1: Orçamento e Fundo -

Saldos consolidados $(\mathbf{R} \$ \mathbf{1 . 0 0 0})$

\begin{tabular}{|c|c|c|c|c|c|c|c|}
\hline Período & \begin{tabular}{|c|} 
Saldo \\
Orçamento
\end{tabular} & \begin{tabular}{|c} 
Saldo \\
Fundo A
\end{tabular} & $\begin{array}{l}\text { Saldo } \\
\text { Fundo B }\end{array}$ & $\begin{array}{l}\text { Saldo Total A } \\
\text { V. Correntes }\end{array}$ & $\begin{array}{l}\text { Saldo Total B } \\
\text { V. Correntes }\end{array}$ & $\begin{array}{l}\text { Saldo total A } \\
\text { V. Presentes }\end{array}$ & $\begin{array}{l}\text { Saldo total B } \\
\text { V. Presentes }\end{array}$ \\
\hline 1 & -12.393 & 33.423 & 34.016 & 21.030 & 21.624 & 21.030 & 21.624 \\
\hline 2 & -10.913 & 28.562 & 29.771 & 17.649 & 18.859 & 16.650 & 17.791 \\
\hline 3 & -9.287 & 22.751 & 24.601 & 13.464 & 15.314 & 11.983 & 13.629 \\
\hline 4 & -7.512 & 16.704 & 19.219 & 9.192 & 11.707 & 7.718 & 9.829 \\
\hline 5 & -5.580 & 10.411 & 13.616 & 4.831 & 8.037 & 3.827 & 6.366 \\
\hline 6 & -3.485 & 1.885 & 6.025 & -1.601 & 2.539 & -1.196 & 1.898 \\
\hline 7 & 1.893 & -7.257 & -2.146 & -5.364 & -254 & -3.782 & -179 \\
\hline 8 & 7.552 & -16.760 & -10.642 & -9.208 & -3.090 & -6.124 & -2.055 \\
\hline 9 & 13.502 & -26.638 & -19.474 & -13.135 & -5.972 & -8.241 & -3.747 \\
\hline 10 & 19.754 & -36.902 & -28.653 & -17.148 & -8.899 & -10.150 & -5.268 \\
\hline 11 & 23.985 & -49.741 & -40.127 & -25.756 & -16.142 & -14.382 & -9.014 \\
\hline 12 & 31.880 & -63.392 & -52.360 & -31.512 & -20.480 & -16.600 & -10.789 \\
\hline 13 & 40.174 & -77.570 & -65.068 & -37.396 & -24.894 & -18.585 & -12.371 \\
\hline 14 & 48.881 & -92.294 & -78.266 & -43.413 & -29.385 & -20.354 & -13.777 \\
\hline 15 & 58.016 & -107.581 & -91.971 & -49.566 & -33.955 & -21.923 & -15.018 \\
\hline 16 & 65.261 & -121.055 & -104.069 & -55.794 & -38.808 & -23.281 & -16.193 \\
\hline 17 & 69.216 & -134.681 & -116.269 & -65.465 & -47.053 & -25.770 & -18.522 \\
\hline 18 & 73.463 & -148.813 & -128.924 & -75.350 & -55.461 & -27.982 & -20.596 \\
\hline 19 & 78.015 & -163.469 & -142.050 & -85.454 & -64.035 & -29.938 & -22.434 \\
\hline 20 & 82.882 & -178.664 & -155.660 & -95.782 & -72.778 & -31.657 & -24.054 \\
\hline 21 & 89.048 & \begin{tabular}{|l|}
-191.778 \\
\end{tabular} & -167.426 & -102.730 & -78.378 & -32.032 & -24.439 \\
\hline 22 & 91.520 & \begin{tabular}{|l|}
-204.962 \\
\end{tabular} & -179.215 & -113.442 & -87.695 & -33.369 & -25.796 \\
\hline 23 & 94.202 & -218.611 & -191.423 & -124.409 & -97.221 & -34.524 & -26.979 \\
\hline 24 & 97.104 & -232.743 & -204.063 & -135.639 & -106.959 & -35.510 & -28.002 \\
\hline 25 & 100.234 & -247.372 & -217.149 & -147.137 & -116.915 & -36.340 & -28.875 \\
\hline 26 & 102.244 & -256.693 & -225.524 & -154.448 & -123.280 & -35.986 & -28.724 \\
\hline 27 & 95.632 & -265.399 & -233.258 & -169.767 & -137.626 & -37.317 & -30.252 \\
\hline 28 & 88.910 & -274.367 & -241.225 & -185.457 & -152.314 & -38.458 & -31.585 \\
\hline 29 & 82.079 & -283.603 & -249.430 & -201.525 & -167.352 & -39.424 & -32.739 \\
\hline 30 & 75.137 & -293.116 & -257.883 & -217.979 & -182.746 & -40.229 & -33.727 \\
\hline Somatório & & & & & & -561.947 & -393.997 \\
\hline
\end{tabular}

Os dois somatórios ( $\mathrm{R} \$ 561.947$ mil e R\$393.997 mil) são os montantes requeridos para fundar o novo sistema, a preços de 1998, sob condições de igualdade entre salários e aposentadorias, brutos e líquidos, e na hipótese de invariabilidade das transferências tributárias e dos vencimentos reais. Para colocar esses valores em proporção, basta lembrar que 
transferências estimadas de ICMS para a Unicamp em 1998 atingem

$\mathrm{R} \$ 381.695$ mil; vale dizer, a universidade necessita de uma quantia superior a um orçamento anual para garantir a transição para um regime previdenciário auto-sustentado.

A seguir são apresentados alguns resultados obtidos com valores e hipóteses alternativos, acompanhados por comentários sobre as variáveis críticas.

\subsection{Igualdade entre aposentadorias e salários brutos ou líquidos}

O saldo $A$ assume a igualdade entre os salários e benefícios brutos, e não líquidos. Essa regra subentende que, ao aposentar-se, o servidor obtém um ganho de renda líquida em relação à posição na atividade, pois deixa de descontar para a previdência. $O$ saldo $B$ extingue a vantagem, sem impor nenhum ônus adicional ao servidor. Como se pode ver, a diferença entre os saldos $A$ e $B$ é muito expressiva. Basta referir a regra de equivalência aos vencimentos líquidos, e não aos brutos, para que se obtenha um grande abatimento nos recursos necessários. Ao invés de se reduzir o valor líquido das aposentadorias, uma alternativa com o mesmo efeito é a imposição de um gravame previdenciário aos já aposentados.

\subsection{Alíquotas de contribuição}

A elevação das alíquotas dos atuais $8 \%+8 \%$ para $12 \%+12 \%$ foi, como se disse, arbitrária. $\mathrm{O}$ mais apropriado seria estimar a alíquota de equilíbrio atuarial para os novos servidores e estendê-la para os demais, já que estamos assumindo idêntica contribuição em ambos os quadros. De todo modo, $24 \%(12+12)$ é uma contribuição elevada em relação às práticas habituais, e uma superação desse teto implicaria uma redução acentuada do salário líquido do servidor.

É importante notar que as alíquotas de contribuição definem tanto a disponibilidade de recursos no fundo quanto o custo da folha de pagamentos, para não falarmos do salário líquido do servidor. No modelo consolidado de orçamento e fundo as contribuições atuam a débito e a crédito - uma alíquota maior traz novos recursos para o fundo, mas projeta uma elevação do ônus no orçamento. Esse duplo impacto, a débito e a crédito, atenua os efeitos das variações de alíquota e diminui o custo orçamentário da adoção de alíquotas menores, em particular no conceito $A$ (equivalência entre salários e aposentadorias brutas). Já uma redistribuição interna da alíquota total de contribuição em favor dos servidores imporia à universidade um ônus acentuado.

A Tabela 2 resume as simulações com alíquotas na vizinhança dos $12 \%$, contemplando também uma alteração na distribuição de contribui- 
ções, em prejuízo do empregador $(14+10)$. Como se pode ver, mantida uma contribuição empregado/empregador equilibrada, a necessidade de recursos a valor presente altera-se de modo quase desprezível, no conceito $A$, e em torno de 3,6\% para cada ponto percentual, no conceito $B$. A diminuição da contribuição dos servidores (hipótese $14+10$ ) afeta a necessidade de recursos orçamentários de modo significativo.

Tabela 2: Necessidade de recursos a valor presente (R\$ 1.000) - Diversas alíquotas de contribuição

\begin{tabular}{ccc}
\hline Alíquotas \% & $\begin{array}{c}\text { Saldo Total A Valores } \\
\text { presentes }\end{array}$ & $\begin{array}{c}\text { Saldo Total B Valores } \\
\text { presentes }\end{array}$ \\
\hline $11+11$ & 562.254 & 408.300 \\
$12+12$ & 561.947 & 393.997 \\
$13+13$ & 561.640 & 379.694 \\
$14+10$ & 627.328 & 487.370 \\
\hline
\end{tabular}

\subsection{Taxa de descontos}

A taxa de descontos é o ponto crítico em modelos que abrangem um intervalo tão longo. A Tabela 3 sintetiza os valores dos saldos totais a valor presente nos conceitos $A$ e $B$ para valores limítrofes da taxa de descontos:

Tabela 3: Necessidade de recursos a valor presente (R\$ 1.000) - Diversas taxas de desconto

\begin{tabular}{ccc}
\hline Taxa de descontos & $\begin{array}{c}\text { Saldo Total A Valores } \\
\text { presentes }\end{array}$ & $\begin{array}{c}\text { Saldo Total B Valores } \\
\text { presentes }\end{array}$ \\
\hline $5 \%$ & 695.154 & 496.604 \\
$6 \%$ & 561.947 & 393.997 \\
$7 \%$ & 455.004 & 312.040 \\
\hline
\end{tabular}

A razão pela qual a elevação da taxa de descontos diminui a necessidade global de recursos a valor presente pode ser intuída facilmente: como os resultados negativos são dominantes e crescentes (em valor modular) no sentido do final das colunas de saldos consolidados, estamos descontando prejuízos crescentes a fatores crescentes. Saldos inicialmente negativos e depois positivos produziriam o resultado inverso. 
A sensibilidade dos resultados a pequenas variações da taxa de descontos, no entanto, não deixa de ser impressionante. Sem entrar em uma discussão mais acurada sobre a taxa de descontos apropriada, é conveniente ao menos observar que teremos aí o fator decisivo na elaboração de cenários de necessidade de recursos, quando estiverem em jogo propostas concretas de mudanças do regime. Uma taxa de descontos convenientemente alta pode reduzir o custo da transição a zero. Uma taxa de descontos de $10 \%$ ao ano, por exemplo, reduziria a necessidade de recursos nos conceitos $A$ e $B$ a $\mathrm{R} \$ 242.129$ e $\mathrm{R} \$ 150.637 \mathrm{mil}$, respectivamente.

\subsection{Progressão dos salários}

As taxas médias anuais de progressão salarial adotadas $-2,5 \%$ para os docentes e 1,1\% para os não-docentes — podem ser criticadas por parecerem excessivamente brandas. Afinal, apenas os quinqüênios e a sexta-parte proporcionam um ganho salarial de 45 a $50 \%$ para o servidor que cumprir a carreira integralmente no serviço público estadual. Além disso, existe ainda progressão funcional e incorporação das gratificações de chefia.

As taxas de $2,5 \%$ e $1,1 \%$ foram obtidas com base na relação entre os vencimentos médios dos servidores inativos e ativos existente em $t_{0}$, e tomando-se um servidor representativo no meio da carreira, sob o ponto de vista dos acréscimos salariais (ver Variáveis e Anexo 1). Salvo mudanças na legislação, acreditamos que a progressão salarial dos servidores do quadro de transição possa vir a ser maior do que a observada, já que a concentração de contratações nos anos 1982/88 vai intensificar a obtenção de sexta-parte entre os anos 2000 e 2005. De todo modo, tanto no quadro de transição quanto no quadro dos servidores a serem contratados, a progressão salarial efetiva é uma variável de difícil estimação, pois depende da rotatividade da mão-de-obra e da situação individual de cada servidor no momento da contratação (idade, empregador anterior, qualificação). Não se consegue ter nenhum controle sobre quaisquer desses dois conjuntos de fatores, sendo que o último afeta substancialmente a taxa média de progressão salarial.

Para mostrar a importância da taxa de progressão salarial média, a Tabela 4 considera três cenários alternativos para a taxa de crescimento da folha dos não-docentes do quadro de transição $(1,1 ; 1,5 \mathrm{e}$ $2 \%$ ), mantida a taxa de crescimento da folha dos docentes utilizada na simulação original $(2,5 \%)$. 
Tabela 4: Necessidade de recursos a valor presente

(R\$ 1.000) - Diversas taxas de progressão salarial no quadro de transição (servidor não-docente)

\begin{tabular}{ccc}
\hline $\begin{array}{c}\text { Progressão salarial (taxa } \\
\text { anual \%) }\end{array}$ & $\begin{array}{c}\text { Saldo Total A Valores } \\
\text { presentes }\end{array}$ & $\begin{array}{c}\text { Saldo Total B Valores } \\
\text { presentes }\end{array}$ \\
\hline 1.1 & 561.947 & 393.997 \\
1.5 & 646.525 & 474.622 \\
2.0 & 758.659 & 581.372 \\
\hline
\end{tabular}

Não se deve esquecer que a taxa média de progressão salarial do quadro de servidores contratados no novo regime também é uma variável importante. No modelo, ela está vinculada às taxas médias de progressão no quadro de transição; mais precisamente, é a média geométrica daquelas taxas. Assim, as variações de taxas simuladas na Tabela 4, referentes aos servidores do quadro de transição, afetam a taxa média de progressão no novo quadro, acentuando os efeitos globais. Na Tabela 5, mantivemos os valores da simulação original para o quadro de transição $(2,5 \%$ e $1,1 \%)$ e arbitramos variações independentes na taxa média de progressão dos servidores do novo quadro. Como se pode ver, alterações apenas nessa taxa também projetam impactos consideráveis na necessidade de recursos.

Tabela 5: Necessidade de recursos a valor presente $(\mathbf{R} \$ 1.000)$ - Diversas taxas de progressão salarial no novo quadro

\begin{tabular}{ccc}
\hline $\begin{array}{c}\text { Progressão salarial (taxa } \\
\text { anual - \%) }\end{array}$ & $\begin{array}{c}\text { Saldo Total A Valores } \\
\text { presentes }\end{array}$ & $\begin{array}{c}\text { Saldo Total B Valores } \\
\text { presentes }\end{array}$ \\
\hline 1.5 & 543.836 & 375.886 \\
2.0 & 574.633 & 306.683 \\
2.5 & 607.316 & 439.367 \\
\hline
\end{tabular}

\subsection{Os vetores}

Os vetores de transição $I, I I$ e $I I I$ da planilha Variáveis só podem ser aperfeiçoados com um acurado estudo demográfico e da situação funcional dos servidores. Pessoalmente, acredito que as taxas assumidas de morte e de passagem à inatividade no quadro de transição aproximam- 
se da realidade. Simulações com mudanças no vetor de aposentadorias no

quadro de transição - o mais sujeito a alterações e o de maior impacto sobre os resultados - afetam significativamente os saldos finais, porque um retardamento ou aceleração das aposentadorias é acompanhado por uma aceleração ou retardamento na incorporação de novos servidores, ou seja, um vetor afeta o outro com efeitos sobrepostos.

$\mathrm{O}$ vetor $I V$, que retrata a incorporação de novos servidores em substituição aos aposentados, foi construído com uma dose talvez exagerada de arbítrio. É verdade que o servidor substituto representa um custo inferior ao aposentado, pois seu salário inicial não incorpora a progressão salarial; ainda assim, o vetor adotado assume uma taxa de reposições defasada nos anos iniciais da transição. A consequiência pode ser vista na tabela Orçamento: nem ao final dos trinta anos — vale dizer, quando os efeitos do crescimento vegetativo na folha dos novos contratados já se teriam feito sentir - a folha de pagamentos atinge os valores observados em 1998. Pode-se dizer que o retardamento da reposição implica um aumento de produtividade do pessoal universitário, já que o volume de serviços é mantido por suposição. Essa é uma hipótese compatível com a percepção geral de que a Unicamp pode enfrentar uma pequena redução de quadros sem prejuízos dramáticos para a qualidade e a extensão dos serviços. De qualquer forma, é bom destacar que essa é uma qualificação importante aos pressupostos iniciais do modelo.

\section{Conclusões e generalização}

Convém lembrar que os resultados da simulação, inclusive o cálculo dos recursos necessários para o equilíbrio do sistema, dependem crucialmente dos valores assumidos para as variáveis. Conforme foi mencionado, os vetores de transição e as taxas de progressão salarial não foram validados por estudos específicos e estão sujeitos à revisão, razões suficientes para que as projeções sejam encaradas com cautela e para que o modelo seja tomado, antes de mais nada, como um instrumento para o aperfeiçoamento da discussão dos regimes de aposentadoria no serviço público.

Feita a ressalva, acredito que o modelo forneça um instrumento operacional hábil para uma primeira avaliação dos custos da transição, aberta a valores alternativos das variáveis. As simulações com valores alternativos mostraram que os resultados são extremamente sensíveis a variações na taxa de descontos, nas taxas de progressão salarial e no vetor de aposentadorias no quadro de transição. Alguns desses fatores podem ser afetados por decisões administrativas e/ou pela legislação. A 
taxa de progressão salarial, por exemplo, depende de leis (as que regem

os adicionais por tempo de serviço), assim como de medidas na esfera da administração universitária (a concessão de gratificações).

O modelo também deixa claro que o equilíbrio previdenciário depende tanto dos tópicos associados ao regime de benefícios - o período e as alíquotas de contribuição, a regra de equivalência entre aposentadorias e salários — como dos que dizem respeito à carreira dos servidores ativos. Surpreendentemente, estes últimos têm sido deixados de lado na discussão sobre os limites do atual sistema. Os fatores que regulamentam a carreira são tão significativos para a solvência do regime previdenciário quanto o período de contribuição, a idade média de aposentadoria, a garantia de vencimentos integrais, enfim, os tópicos previdenciários no sentido estrito. Medidas elementares, como a instituição de uma caixa de compensações para as contribuições à previdência, o controle do passivo previdenciário dos servidores admitidos, ou, ainda, alterações legislativas simples nas normas de concessão e incorporação de gratificações e de progressão por tempo de serviço, provocariam um forte impacto na necessidade de recursos.

O modelo é adaptável a outros segmentos do serviço público, em situações diversas quanto a amadurecimento do quadro de servidores, tabelas de progressão salarial, peso dos inativos na folha de pagamentos etc. Tudo o que se requer é a especificação das fontes de receita, ou a definição de uma regra de participação nos recursos públicos. Acredito que o primeiro passo para o estabelecimento de uma política adequada de custeio e benefício na previdência pública seja exatamente este: a associação entre volume de serviços e dotações orçamentárias. Trata-se de um expediente difícil — mas não impossível — de ser idealizado e testado no serviço público como um todo, mas factível quando já existe uma regra de acesso a recursos, como ocorre com as universidades públicas paulistas.

Embora a política de benefícios admitida na simulação seja a de equivalência entre os vencimentos na atividade e inatividade (nos conceitos bruto e líquido), não há nenhuma dificuldade em simular os resultados de uma política que implante redutores, ou que vincule a aposentadoria ao salário médio de contribuição ao longo da carreira. $\mathrm{O}$ único aspecto incontornável é a solidariedade fundo-orçamento. Na medida em que os vencimentos reais são flexíveis à baixa e em que não existe definição de benefícios, no sentido literal, o procedimento utilizado equivale a hipotecar uma fração determinada do orçamento universitário à transição de regime previdenciário, garantido o nível mínimo dos serviços.

Para concluir, cabe acrescentar que o saldo total consolidado a valores presentes, designado de "custo da transição", não significa "custo de 
implantação do fundo", no rigor da expressão. Na realidade, na vigência do princípio de responsabilidade orçamentária, se o fundo não fosse constituído o resultado seria o mesmo. A necessidade de recursos depende das alíquotas de contribuição, das normas que regem os benefícios e a carreira, da taxa de descontos, ou seja, das variáveis que estão presentes na simulação. É uma questão secundária saber se as contribuições devem ser contabilizadas a crédito (e os benefícios a débito) do orçamento ou do fundo. Se não fosse constituído um fundo, todos os impactos a débito e a crédito seriam contabilizados no orçamento, com resultado final idêntico. A rigor, a própria questão da capitalização é secundária. Já que se trata de um fluxo de saldos ao longo do tempo, é evidente que o planejamento orçamentário e a apuração de resultados requerem a capitalização (ou o desconto) de valores.

A grande virtude de um sistema baseado na separação entre fundo e orçamento é a maior visibilidade conferida aos impactos previdenciários das políticas de pessoal e de benefícios. Uma vez identificadas as fontes de pressão sobre os desembolsos do fundo, a administração pública verse-á obrigada a adotar medidas que imponham maior disciplina atuarial, inclusive - e principalmente - no que se refere às admissões de funcionários, à organização das carreiras e à estrutura salarial. 


\section{Anexo 1 - Dados}

\section{Folha de pagamentos}

O orçamento da Unicamp para 1998 fornece as informações básicas sobre gastos com pessoal, distribuídas nas categorias ativos e inativos, docentes e não-docentes. Os dados sobre valores de folha de pagamentos $\left(\mathrm{FPB}_{\mathrm{DA}}, \mathrm{FPB}_{\mathrm{DI}}, \mathrm{FPB}_{\mathrm{NDA}}, \mathrm{FPB}_{\mathrm{NDI}}\right)$ utilizados nas planilhas foram obtidos deduzindo-se das informações orçamentárias os valores destinados ao PASEP, que não representam custo de folha. $\mathrm{O}$ recolhimento ao PASEP não é uma informação orçamentária e o procedimento adotado foi recolher a informação mais atualizada (dezembro de 1997) para, a partir dela, inferir a dedução a ser imputada aos valores orçamentários de 1998.

\section{Pessoal não-estatutário}

A participação dos não-estatutários na folha é uma informação decisiva para se obter o custo das aposentadorias, já que somente os estatutários são incorporados à folha de benefícios do serviço público. Essa também é uma informação não-orçamentária, fornecida pelo Setor de Recursos Humanos e incorporada ao cálculo da folha líquida na planilha Variáveis $\left(\mathrm{FPL}_{\mathrm{DA}}, \mathrm{FPL}_{\mathrm{NDA}}\right)$.

\section{Progressão salarial ou crescimento vegetativo da folha}

O que foi denominado de progressão salarial ou crescimento vegetativo da folha (crescimento da folha de pagamentos independentemente de reajustes salariais) incorpora a progressão funcional, os adicionais por tempo de serviço e as gratificações. É difícil calcular a taxa de progressão a partir de informações institucionais sobre as carreiras e as regras de atribuição de adicionais por tempo de serviço, porque os acréscimos efetivamente havidos dependem de fatores como rotatividade e situação dos servidores no momento da contratação.

A simulação adotou como critério para o cálculo das taxas de progressão a razão entre vencimentos médios do pessoal ativo e inativo, para docentes e não-docentes. Ajustando-se essas relações $\left(\mathrm{SM}_{\mathrm{DI}} / \mathrm{SM}_{\mathrm{DA}}=\right.$ 1,$\left.46 ; \mathrm{SMN}_{\mathrm{NDI}} / \mathrm{SM}_{\mathrm{NDA}}=1,19\right)$ à extensão de carreira futura estimada para docentes e não-docentes, obtiveram-se as taxas anuais médias de progressão $\left(\mathrm{TMPS}_{\mathrm{D}}=0,025 ; \mathrm{TMPS}_{\mathrm{ND}}=0,011\right)$. A média geral dos docentes 
e não docentes, considerada no cálculo do impacto salarial das novas contratações, é a média geométrica de TMPS $_{\mathrm{D}}$ e TMPS ${ }_{\mathrm{ND}}$.

Para simplificar, a estimativa de tempo de carreira assumiu a figura de um servidor representativo, no meio da carreira, quanto ao usufruto de acréscimos salariais. 
A representação abaixo adota a notação das planilhas de cálculo, com uma adaptação: as colunas são designadas por numerais romanos, e não por letras. Os numerais romanos correspondem aos utilizados na descrição das planilhas, na seção 4 do texto. Na remissão de uma planilha a outra, a indicação da planilha de origem da variável aparece entre traços verticais — |Var|; |Orç|; |Fun|. A ausência de indicação de planilha de origem significa que o numeral da coluna identifica uma variável no interior da própria planilha em que a operação se processa.

\section{Orçamento}

I. Folha salarial dos docentes do quadro de transição - considera os novos encargos e o crescimento vegetativo da folha e desconsidera o efeito das aposentadorias.

$(|\operatorname{Var} \mathrm{I}| *(1+|\operatorname{Var} \mathrm{XIV}|) / 1,08) *(1+|\operatorname{Var} \mathrm{IX}|)^{\mathrm{t}-1}$

II. Folha salarial dos docentes do quadro de transição - considera os novos encargos e o crescimento vegetativo da folha e desconta o efeito das aposentadorias.

\section{I* $(1$ - |Var XVIIIB $\mid)$}

III. Variação da folha de pagamentos dos docentes do quadro de transição em relação ao ano-base.

II - |Var I|

IV. Folha salarial dos não-docentes do quadro de transição - considera os novos encargos e o crescimento vegetativo da folha e desconsidera o efeito das aposentadorias.

$(|\operatorname{Var} \mathrm{III}| *(1+|\operatorname{Var} \mathrm{XIV}|) / 1,08) *(1+|\operatorname{Var} \mathrm{X}|)^{\mathrm{t}-1}$

V. Folha salarial dos não-docentes do quadro de transição - considera os novos encargos e o crescimento vegetativo da folha e desconta e efeito das aposentadorias.

\section{IV * (1 - |Var XVIIIB|)}

VI. Variação da folha dos não-docentes do quadro de transição em relação ao ano-base.

$\mathrm{V}$ - |Var III|

VII. Morte dos servidores inativos no ano-base.

$|\operatorname{Var} \mathrm{XVIIB}| *(|\operatorname{Var} \mathrm{II}|+|\operatorname{Var} \mathrm{IV}|)$

VIII. Novas contratações - impactos sobre a folha ano a ano (sem acumular). 
$(|\operatorname{Var} \mathrm{XII}|+|\operatorname{Var} \mathrm{XIII}|) *(1+|\operatorname{Var} \mathrm{XIV}|) *|\operatorname{Var} \mathrm{XXA}|$

IX. Novas contratações - impactos acumulados sobre a folha, considerando-se a progressão salarial.

No período $t_{1}$ o valor é idêntico ao da mesma linha da coluna anterior (VIII). Nos demais, passam a ser incorporados os efeitos das contratações ano a ano, além da progressão salarial diferenciada conforme o ano de contratação do contingente. As fórmula na linha correspondente a $\mathrm{t}_{2}$ e demais linhas são:

$\mathrm{t}_{2}=|\operatorname{Var} \mathrm{IX}| *(1+\operatorname{Var} \mathrm{XI})^{\mathrm{t}-1} * \mathrm{VIII} \quad \mathrm{t}_{3}, \mathrm{t}_{4}, \ldots .=\mid \mathrm{X}_{\mathrm{t}-1} *(1+\mid \operatorname{Var}$ $\mathrm{XI} \mid)+\mathrm{VIII}_{\mathrm{t}}$

$\mathrm{X}$. Saldo do orçamento.

VII - III - VI - IX

\section{Fundo}

I. Inclusão dos docentes do quadro de transição no fundo (salário bruto integral), excluindo os docentes celetistas.

$|\operatorname{VarXII}| *(1+|\operatorname{VarIX}|)^{t-1} *(1-|\operatorname{VarV}|) *|\operatorname{VarXVIIIB}|$

II. Inclusão dos não-docentes do quadro de transição no fundo (salário bruto integral).

$|\operatorname{VarXIII}| *(1+|\operatorname{VarX}|)^{\mathrm{t}-1} *(1-|\operatorname{VarVI}|) *(|\operatorname{VarXVIIIB}|)$

III. Contribuição correspondente aos docentes do quadro de transição.

$|\operatorname{VarXII}| *(1+|\operatorname{VarIX}|)^{\mathrm{t}-1} *(1-|\operatorname{VarV}|) *(|\operatorname{VarXIV}|+|\operatorname{VarXV}|)$

IV. Contribuição dos não-docentes do quadro de transição ao fundo.

$|\operatorname{VarXIII}| *(1+|\operatorname{VarX}|)^{\mathrm{t}-1} *(1-|\operatorname{Var} \mathrm{VI}|) *(|\operatorname{VarXIV}|+|\operatorname{VarXV}|)$

V. Saldo A

III + IV - I - II integral).

VI. Inclusão dos docentes do quadro de transição (salário líquido

$\mathrm{I} *(1-|\operatorname{Var} \mathrm{XV}|)$

VII. Inclusão dos não-docentes do quadro de transição (salário líquido integral).

II * (1 - |Var XV|)

VIII. Saldo B

III + IV - VI - VII 
Anexo 3 - Tabelas

Tabela A1: Orçamento (R\$ 1.000)

\begin{tabular}{|c|c|c|c|c|c|c|c|c|c|c|}
\hline Período & I & II & III & IV & $\mathbf{V}$ & VI & VII & VIII & IX & $\mathbf{X}$ \\
\hline 1 & 116.599 & 116.599 & 4.164 & 165.113 & 165.113 & 5.897 & 486 & 2.817 & 2.817 & -12.393 \\
\hline 2 & 9.514 & 115.929 & 3.494 & 166.929 & 161.921 & 2.705 & 971 & 2.817 & 5.685 & -10.913 \\
\hline 3 & 122.502 & 115.152 & 2.717 & 168.765 & 158.639 & -577 & 1.457 & 2.817 & 8.604 & -9.287 \\
\hline 4 & 125.565 & 114.264 & 1.829 & 170.622 & 155.266 & -3.950 & 1.943 & 2.817 & 11.576 & -7.512 \\
\hline 5 & 128.704 & 113.259 & 824 & 172.499 & 151.799 & -7.417 & 2.429 & 2.817 & 14.601 & -5.580 \\
\hline 6 & 131.921 & 112.133 & -302 & 174.396 & 148.237 & -10.979 & 2.914 & 2.817 & 17.681 & -3.485 \\
\hline 7 & 135.219 & 109.528 & -2.907 & 176.314 & 142.815 & -16.401 & 3.400 & 2.817 & 20.816 & 1.893 \\
\hline 8 & 138.600 & 106.722 & -5.713 & 178.254 & 137.256 & -21.960 & 3.886 & 2.817 & 24.007 & 7.552 \\
\hline 9 & 142.065 & 103.707 & -8.728 & 180.215 & 131.557 & -27.659 & 4.371 & 2.817 & 27.256 & 13.502 \\
\hline 10 & 145.617 & 100.475 & -11.960 & 182.197 & 125.716 & -33.500 & 4.857 & 2.817 & 30.563 & 19.754 \\
\hline 11 & 149.257 & 97.017 & -15.418 & 184.201 & 119.731 & -39.485 & 5.828 & 5.634 & 36.746 & 23.985 \\
\hline 12 & 152.988 & 91.793 & -20.642 & 186.227 & 111.736 & -47.480 & 6.800 & 5.634 & 43.041 & 31.880 \\
\hline 13 & 156.813 & 86.247 & -26.188 & 188.276 & 103.552 & -55.664 & 7.771 & 5.634 & 49.449 & 40.174 \\
\hline 14 & 160.733 & 80.367 & -32.068 & 190.347 & 95.173 & -64.043 & 8.743 & 5.634 & 55.972 & 48.881 \\
\hline 15 & 164.752 & 74.138 & -38.297 & 192.441 & 86.598 & -72.618 & 9.714 & 5.634 & 62.613 & 58.016 \\
\hline 16 & 168.870 & 67.548 & -44.887 & 194.558 & 77.823 & -81.393 & 11.171 & 8.451 & 72.190 & 65.261 \\
\hline 17 & 173.092 & 62.313 & -50.122 & 196.698 & 70.811 & -88.405 & 12.628 & 8.451 & 81.939 & 69.216 \\
\hline 18 & 177.420 & 56.774 & -55.661 & 198.861 & 63.636 & -95.580 & 14.085 & 8.451 & 91.863 & 73.463 \\
\hline 19 & 181.855 & 50.919 & -61.516 & 201.049 & 56.294 & -102.922 & 15.542 & 8.451 & \begin{tabular}{|l|}
101.966 \\
\end{tabular} & 78.015 \\
\hline 20 & 186.401 & 44.736 & -67.699 & 203.260 & 48.783 & -110.433 & 17.000 & 8.451 & \begin{tabular}{|l|}
112.250 \\
\end{tabular} & 82.882 \\
\hline 21 & 191.061 & 38.212 & -74.223 & 205.496 & 41.099 & -118.117 & 19.428 & 8.451 & 122.719 & 89.048 \\
\hline 22 & 195.838 & 33.292 & -79.143 & 207.757 & 35.319 & \begin{tabular}{|l|}
-123.897 \\
\end{tabular} & 21.857 & 8.451 & \begin{tabular}{|l|}
133.376 \\
\end{tabular} & 91.520 \\
\hline 23 & 200.734 & 28.103 & -84.332 & 210.042 & 29.406 & -129.810 & 24.285 & 8.451 & 144.225 & 94.202 \\
\hline 24 & 205.752 & 22.633 & -89.802 & 212.353 & 23.359 & -135.857 & 26.714 & 8.451 & \begin{tabular}{|l|}
155.269 \\
\end{tabular} & 97.104 \\
\hline 25 & 210.896 & 16.872 & -95.563 & 214.688 & 17.175 & -142.041 & 29.142 & 8.451 & \begin{tabular}{|l|}
166.512 \\
\end{tabular} & 100.234 \\
\hline 26 & 216.169 & 10.808 & -101.627 & 217.050 & 10.853 & -148.363 & 33.028 & 11.268 & 180.773 & 102.244 \\
\hline 27 & 221.573 & 8.863 & -103.572 & 219.438 & 8.778 & \begin{tabular}{|l}
-150.438 \\
\end{tabular} & 36.913 & 11.268 & 195.292 & 95.632 \\
\hline 28 & 227.112 & 6.813 & -105.622 & 221.851 & 6.656 & -152.560 & 40.799 & 11.268 & \begin{tabular}{|l|}
210.071 \\
\end{tabular} & 88.910 \\
\hline 29 & 232.790 & 4.656 & -107.779 & 224.292 & 4.486 & -154.730 & 44.684 & 11.268 & 225.115 & 82.079 \\
\hline 30 & 238.610 & 2.386 & -110.049 & 226.759 & 2.268 & -156.948 & 48.570 & 11.268 & 240.430 & 75.137 \\
\hline
\end{tabular}


Tabela A2: FUNDO (R\$ 1.000)

\begin{tabular}{|c|c|c|c|c|c|c|c|c|}
\hline Período & I & II & III & IV & $\mathbf{V}$ & VI & VII & VIII \\
\hline 1 & 2.998 & 1.946 & 23.267 & 15.101 & 33.423 & 2.638 & 1.712 & 34.016 \\
\hline 2 & 6.146 & 3.935 & 23.848 & 14.795 & 28.562 & 5.409 & 3.463 & 29.771 \\
\hline 3 & 9.450 & 5.967 & 23.688 & 14.480 & 22.751 & 8.316 & 5.251 & 24.601 \\
\hline 4 & 12.915 & 8.044 & 23.506 & 14.157 & 16.704 & 11.365 & 7.078 & 19.219 \\
\hline 5 & 16.548 & 10.165 & 23.299 & 13.825 & 10.411 & 14.562 & 8.945 & 13.616 \\
\hline 6 & 21.484 & 13.017 & 23.067 & 13.319 & 1.885 & 18.906 & 11.455 & 6.025 \\
\hline 7 & 26.658 & 15.931 & 22.531 & 12.800 & -7.257 & 23.459 & 14.020 & -2.146 \\
\hline 8 & 32.076 & 18.908 & 21.954 & 12.269 & -16.760 & 28.227 & 16.639 & -10.642 \\
\hline 9 & 37.749 & 21.948 & 21.334 & 11.724 & -26.638 & 33.219 & 19.314 & -19.474 \\
\hline 10 & 43.685 & 25.052 & 20.669 & 11.166 & -36.902 & 38.443 & 22.046 & -28.653 \\
\hline 11 & 51.174 & 28.946 & 19.958 & 10.421 & -49.741 & 45.033 & 25.472 & -40.127 \\
\hline 12 & 59.010 & 32.922 & 18.883 & 9.657 & -63.392 & 51.929 & 28.972 & -52.360 \\
\hline 13 & 67.206 & 36.983 & 17.742 & 8.876 & -77.570 & 59.141 & 32.545 & -65.068 \\
\hline 14 & 75.774 & 41.129 & 16.533 & 8.076 & -92.294 & 66.681 & 36.193 & -78.266 \\
\hline 15 & 84.729 & 45.361 & 15.251 & 7.258 & -107.581 & 74.562 & 39.918 & -91.971 \\
\hline 16 & 92.638 & 48.917 & 13.896 & 6.604 & -121.055 & 81.521 & 43.047 & -104.069 \\
\hline 17 & 100.888 & 52.546 & 12.819 & 5.935 & -134.681 & 88.781 & 46.241 & -116.269 \\
\hline 18 & 109.493 & 56.249 & 11.679 & 5.250 & -148.813 & 96.354 & 49.499 & -128.924 \\
\hline 19 & 118.466 & 60.027 & 10.475 & 4.549 & -163.469 & 104.250 & 52.824 & -142.050 \\
\hline 20 & 127.818 & 63.882 & 9.203 & 3.833 & -178.664 & 112.480 & 56.216 & -155.660 \\
\hline 21 & 135.927 & 67.006 & 7.861 & 3.294 & -191.778 & 119.615 & 58.966 & -167.426 \\
\hline 22 & 144.361 & 70.192 & 6.849 & 2.742 & -204.962 & 127.037 & 61.769 & -179.215 \\
\hline 23 & 153.131 & 73.440 & 5.781 & 2.178 & -218.611 & 134.756 & 64.627 & -191.423 \\
\hline 24 & 162.250 & 76.750 & 4.656 & 1.602 & -232.743 & 142.780 & 67.540 & -204.063 \\
\hline 25 & 171.730 & 80.125 & 3.471 & 1.012 & -247.372 & 151.122 & 70.510 & -217.149 \\
\hline 26 & 177.876 & 81.859 & 2.223 & 819 & -256.693 & 156.531 & 72.036 & -225.524 \\
\hline 27 & 184.222 & 83.621 & 1.823 & 621 & -265.399 & 162.115 & 73.587 & -233.258 \\
\hline 28 & 190.774 & 85.413 & 1.402 & 418 & -274.367 & 167.881 & 75.163 & -241.225 \\
\hline 29 & 197.539 & 87.233 & 958 & 211 & -283.603 & 173.834 & 76.765 & -249.430 \\
\hline 30 & 204.523 & 89.084 & 491 & 0 & -293.116 & 179.980 & 78.394 & -257.883 \\
\hline
\end{tabular}


1 A instituição de uma idade mínima para a aposentadoria dos servidores do quadro de transição não afeta de modo significativo a Unicamp.

2 Adiante será feita uma discussão mais pormenorizada sobre o regime de benefícios definidos.

3 É bom observar que o modelo opera com uma hipótese de rigidez dos salários à alta.

4 Os vencimentos de referência estão protegidos contra baixas não relacionadas à queda dos recursos tributários.

5 O governo do Estado promoveu uma alteração da legislação, atenuando o efeito da incorporação. As universidades mantiveram a sistemática de incorporação aos 5 anos. Até o momento, o governo estadual não cogitou de alterar a concessão de acréscimos salariais por quinquênios, e nem mesmo de extinguir a sexta parte.

6 A alternativa mais simples seria aplicar os adicionais por tempo de serviço à carreira restante do servidor, mas ela desconsidera a progressão funcional, a incorporação de gratificações e a existência de alguma rotatividade da mão-de-obra entre os não-docentes.

7 A proporção da folha aplicada ao pagamento de servidores celetistas foi extrapolada a partir de dados de dezembro de 1997 (ver Anexo 1).

8 Maiores esclarecimentos sobre as variáveis no Anexo 1.

9 Para os docentes, supusemos uma carreira média de 30 anos, o que pressupõe uma distribuição equilibrada entre os gêneros e entre professores que se beneficiam da aposentadoria especial (25/30 anos) e não se beneficiam (30/35 anos).

${ }^{10}$ Para os não-docentes, supusemos uma carreira média de 32 anos, o que pressupõe uma distribuição equilibrada entre os gêneros. 


\section{Fundo previdenciário e impacto orçamentário no serviço público Mauricio C. Coutinho}

$\mathrm{O}$ trabalho discute as características do regime previdenciário no serviço público e efetua uma simulação do custo orçamentário da transição, para o caso da Universidade Estadual de Campinas (Unicamp). Já que a Unicamp, em particular, e o serviço público, de modo geral, encontram-se na expectativa da transição de regime previdenciário, a simulação estima os custos de inclusão dos servidores ativos em novas regras, mantidos como parâmetros a vinculação entre os vencimentos na atividade e na inatividade e a garantia orçamentária dos benefícios.

\section{Fundo previdenciário e impacto orçamentário no serviço público Mauricio C. Coutinho}

El trabajo mide los costos de la transición de régimen de seguridad social en lo sector público brasileño, apoyado en un estudio de caso de la Universidade Estadual de Campinas. El modelo que resulta del estudio puede ser estendido a otros ramos del servicio público, bajo la condición de "solidariedad presupuestaria", es decir, en situaciones en que el empleador garantize la solvencia del fondo de beneficios

El propósito final del trabajo es ampliar la presente discussion respecho la política de jubilamiento de los empleados del sector público. En la medida en que el estudio de caso muestra que factores ligados a la estructura de las carreras - adicionales a cada 5 años de servicio, política de promociones, condiciones de contractación - son tan decisivos en la definición del costo de la proteción social quanto las leyes que determinan los benefícios, el trabajo concluye que aquellos factores deben ser estudiados con tanta atención quanto las conocidas disfuncciones de las políticas de jubilamiento, propriamente dichas.

\section{A social security fund and budgetary impact on the public service \\ Mauricio C. Coutinho}

The paper estimates the conditions and consequences of reforming the social security system within the Brazilian public service, by means of a case study of the Universidade Estadual de Campinas. The model devised may be applied to other branches of the public service, provided there is "budget commitment", that is, a situation in which the employer ultimately props the fund.

The ultimate goal of the paper is the widening of the arguments concerning the ongoing discussion of the public servants social security. As far as the case study shows that many factors underlying the career structure are as important as the social security policy properly in defining the costs of the retirement policies, the paper attempts to shift the debate, considering the role of those factors instead of focusing in the ill designed benefits and retirement policies only.
Revista do

Serviço

Público

Ano 50

Número 1

Jan-Mar 1999

Professor adjunto do Instituto de Economia da Universidade Estadual de Campinas/ Unicamp 